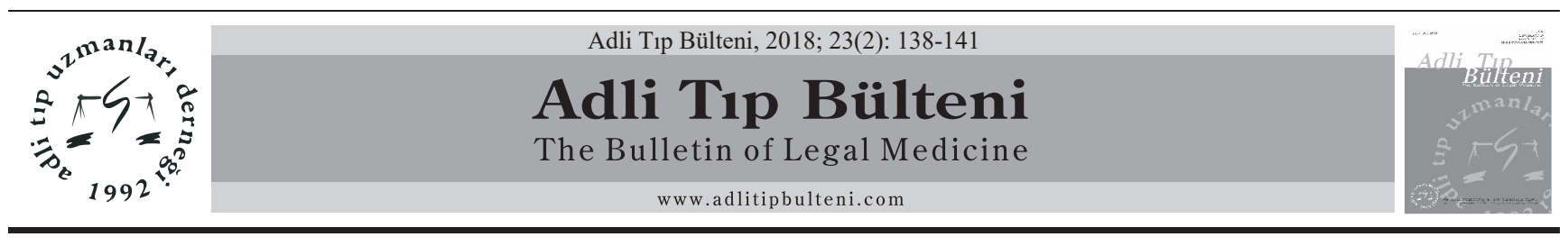

OLGU SUNUMU / CASE REPORT

doi: 10.17986/blm.2016241708

\title{
Adli Otopsi İle Saptanan Şiloperikardiyum
}

\section{Chylopericardium Detected by Forensic Autopsy}

\author{
Ertuğrul Gök', Recep Fedakar², Okan Akan ${ }^{3}$ \\ ${ }^{I}$ Adli Tip Kurumu Samsun Şube Müdürlüğü, Samsun \\ ${ }^{2}$ Uludă̆ Üniversitesi Tip Fakültesi Adli Tip Anabilim Dalı, Bursa \\ ${ }^{3}$ Adli Tıp Kurumu Bursa Grup Başkanlı̆̆ı, Bursa
}

\begin{abstract}
Özet
$\mathrm{Bu}$ sunumda adli otopside şiloperikardiyum saptanan 72 yaşındaki kadın olguyu medikolegal boyutuyla sunarak tartışmayı ve kısa literatür incelemesi yapmayı amaçladık. Basit bir tıbbi müdahale ile giderilebilecek nitelikte yaralanmaya maruz kaldı$\breve{g} 1$ darp olayından 5 gün sonra gastrointestinal sistem şikayetleri nedeniyle bir hastaneye başvurmuştur. İnsizyonel herni ve kolon divertikül perforasyonu cerrahi tedavisi sonrası hemodinamisi stabil olarak klinikte takip ve tedavileri devam ederken, hastaneye yatışının ikinci gününde ölmüştür. Otopsisinde iç muayenede, perikardın gergin ve boşluğunun beyaz renkli şilöz sıvı ile dolu olduğu görüldü. Batında cerrahi sütüre yara, ekimoz, membran ve noktasal kanama alanları ile adhesiv alanlar izlendi. Makroskobik olarak yoğun peritonit bulgusu izlenmedi. Histopatolojik incelemede; akciğerlerde ödem, kalpte myosit sitoplazmalarında genişleme, ince ve kalın bağırsaklarda serozal yüzde yoğun nötrofil lökosit infiltrasyonu, sütür materyali yanısıra nonspesifik bulgular saptandı. Kimyasal analizlerde herhangi bir toksik madde saptanmadı. Perikard boşluğundan alınan sıvının biyokimyasal analizinde; $461 \mathrm{mg} / \mathrm{dL}$ trigliserid ve $114 \mathrm{mg} / \mathrm{dL}$ kolesterol saptand1. Kişinin ölüm nedeni "insizyonel herni, divertikül perforasyonu, ileus ve gelişen komplikasyonlar sonucu" olarak raporlandı. Otopside saptanan şiloperikardiyum ile kişinin hayatta iken maruz kalmış olduğu darp arasında nedensellik bağı kurulamadı. Şiloperikardiyumun kişinin geçirmiş olduğu cerrahi tedaviye sekonder geliştiği kanaatine varıldı.
\end{abstract}

Anahtar Kelimeler: Künt Travma; Otopsi; Şiloperikardiyum; Nedensellik Bağı.

\begin{abstract}
The purpose of this case report is to discuss a case of a 72-yearold woman with chylopericardium determined at forensic autopsy, together with the medicolegal dimensions and a brief review of the literature. She presented to a hospital with gastrointestinal symptoms five days after an assault resulting in injury that could have been resolved with a simple medical intervention. Following surgical treatment of incisional hernia and perforated colonic diverticulitis, the patient's hemodynamics were stable, and monitoring and treatment were maintained. However, the patient died on the second day of hospitalization. Autopsy revealed that the pericardium was tense and that the cavity was filled with white, chylous fluid. A surgically sutured wound, areas of ecchymosis, membrane and point hemorrhage and adhesive areas were observed in the abdomen. No significant macroscopic findings of peritonitis were observed. Histopathological examination revealed edema in the lungs, expansion of the myocyte cytoplasm in the heart, intensive neutrophil and leukocyte infiltration in the serosal surface in the small and large bowels, and nonspecific findings in addition to the suture material. No toxic substance was determined at chemical analyses. Biochemical analysis of fluid from the pericardial cavity revealed levels of $461 \mathrm{mg} / \mathrm{dL}$ triglyceride and $114 \mathrm{mg} / \mathrm{dL}$ cholesterol. Cause of death was reported as "incisional hernia, diverticular perforation, ileus and ensuing complications". No causal relation was established between the chylopericardium identified at autopsy and the assault occurring while the patient was alive. It was concluded that the chylopericardium developed secondary to surgical treatment.
\end{abstract}

Keywords: Blunt Trauma; Autopsy; Chylopericardium; Causal Link.

kardiyum, primer oluşabileceği gibi bir patolojiye sekonder olarak da gelişebilir. Olgumuzu medikolegal açıdan irdeleyerek şiloperikardiyuma yönelik kısa literatür taraması sunmayı amaçladık.

\section{Olgu}

Adli Tıp Kurumu Bursa Grup Başkanlığı Morg İhtisas Dairesi'ne gönderilen 72 yaşındaki kadın olgunun adli tahkikat ve tıbbi evrakı, otopsi bulguları, histopatolojik 
inceleme bulguları ile sistematik toksikolojik analiz sonuçları ve İstanbul Adli Tıp Kurumu Başkanlığı, Birinci Adli Tıp İhtisas Kurulu raporu incelendi.

Adli tahkikat evrakının incelenmesinde; evinde yalnız yaşayan olgunun, aynı zamanda komşusu olan akrabaları tarafından darp edildiği iddiasıyla jandarmaya suç duyurusunda bulunduğu saptandi. İfade tutanağında; olgunun boğazının sıkıldığı, sürüklendiği, kafasının betona vurulduğu ve üzerine çıkılarak çiğnendiği bilgileri mevcuttu. Aynı gün düzenlenmiş genel adli muayene raporunda, olgunun: bilincinin açık, genel durumunun iyi; sol önkolda 1-2 cm'lik ekimozlu sıyrık, sol el 1. parmakta 1-2 cm'lik sıyrık; çekilen direkt grafilerinin normal olduğu, torakal ve abdominal bölgelerde makroskobik muayene bulgusu olmadığı, bu bulgular dışında olgunun saçlı derisinde hassasiyet tarif ettiği tespit edildi.

Olgu, basit bir tıbbi müdahale ile giderilebilecek ölçüde hafif yaralanmaya maruz kaldığı darp olayından 5 gün sonra, karın ağrısı ve kusma şikâyetleri nedeniyle bir hastaneye götürülmüş. Genel Cerrahi uzmanı tarafından yapılan muayenede; karında 10x10 cm boyutunda insizyonel herni, defans ve bağırsak seslerinde azalma saptanan olgu "insizyonel herni ve kolon divertikül perforasyonu" nedeniyle ameliyat edilmiş. Ameliyat notunda; batın içinde inkarsere omentum, cerahat, sporadik organ yapışıklıkları, sigmoid kolon orta ön tarafta 2-3 mm perforasyon alanı ve iltihaplı sıvı saptandığı ve perforasyonun divertikülden kaynaklandığının tespit edildiği ifade edilmektedir. Cerrahi tedavisi sonrası yoğun bakımda hemodinamisi stabil olarak takip ve tedavileri devam ederken, hastaneye yatışının ikinci gününde, ani kardiyak arrest gelișen olgunun, kardiyopulmoner resüsitasyona ve ilaç tedavisine rağmen yaşamını kaybettiği kayıtlıdır. Olgunun tıbbi özgeçmişinde; hipertansiyon, diyabetes mellitus ile geçirilmiş total abdominal histerektomi ve bilateral salpingoooferektomi bulunmaktadır.

Cumhuriyet Savcılığı, kișinin kesin ölüm nedeninin ve ölümü ile maruz kalmış olduğu darp olayı arasında illiyet olup olmadığının saptanması amacıyla adli otopsi yapılmasını talep etmiştir.

Otopside; boyun sağ yanda sütüre $0.5 \mathrm{~cm}$ 'lik yara, sağ omuz üzerinde $2 \times 1 \mathrm{~cm}$ 'lik ekimoz, her iki dirsek büklümünde ve her iki el bileğinde ekimozlu enjeksiyon izleri, sol ön kol posterolateral üst alanda $3.5 \times 2 \mathrm{~cm}$ 'lik yeşil- mor ekimoz, sağ ön kol lateralde üst uca yakın alanda $2.5 \times 2.5 \mathrm{~cm}$ 'lik yeşil renkli ekimoz, sağ ön kol distalde $0.5 \times 1$ cm'lik, $2.5 \times 0.5$ cm'lik, sağ el sırtında $4.5 \times 2$ cm'lik, sol el sırtında $4 \times 5 \mathrm{~cm}$ 'lik ekimozlar, sağ el lateralde 1 cm'lik kabuklu sıyrı, sol el 1. metakarp dorsalinde 1 cm'lik sıyrık, batın orta hatta dikey seyirli üzeri sütürlü $15 \mathrm{~cm}$ 'lik ameliyat yarası, bu yaranın her iki lateralinde sağ taraftaki sütürlü, soldaki sütürsüz, 1.5 $>\mathrm{er} \mathrm{cm}$ 'lik drene ait olduğu muhtemel yaralar, göbek etrafında ameliyat yarası çevresinde yeşil renkte ekimozlar tespit edildi. İç muayenede; beyin beyincik kesitlerinde ödem, meningeal damarlarda belirginleşme, Willis poligonunda minimum aterosklerotik değişiklikler saptandı. Sternum korpusunda hafif içe açılanma izlendi, sağ plevral boșluktan $150 \mathrm{~mL}$ ve sol plevral boşluktan 100-150 mL kadar seröz vasıfta sıvı boşaltıldı. Perikardın gergin olduğu ve diseksiyonunda; perikard boşluğunun beyaz renkli, şilöz sıvı ile dolu olduğu tespit edildi (Resim 1). Kalp 380 gram ağırlığında tartıldı. Sağ atrium çevresinde yoğun beyaz renkli sıvı bulaşığı, kalp posterior yüzeyinde üstte noktasal peteşiler, epikardiyal yağ dokusunda yer yer kontüzyon alanları izlendi. Arcus aortada belirginleşme, lümeninde minimal aterosklerotik değişiklikler saptandı. Sol sirkumfleks arterde ve sağ koroner arterde tıkayıcı olmayan aterom plakları izlendi, sol ön inen arterin ise açık olduğu, aort kapakçıklarında sertleşmeler olduğu, myokard kesitlerinin doğal olduğu tespit edildi. Akciğer kesitlerinin yoğun antrakotik, az miktarda ödemli ve konjesyone görünümde olduğu saptandı. Batında ameliyat yarasına uyan cilt altı ve kas dokusunda kanama alanları olduğu, periton üzerine yama (mesh) yerleştirildiği, omentum üzerinde membranlar ve peteşiler görüldü. Bağırsak seroz zarları üzerinde ekimozlu alanlar, ince bağırsaklarda adhesiv alanlar ve mezenterde sporadik membranla kaplı alanlar görüldü. Sigmoid kolon çevresinde batın içinde yapışıklıklar ve sütüre alanlar saptandı. Sigmoid kolon seröz zarında sütüre alan bulundu. Karaciğer yüzey ve kesitlerinin yağ $l_{1}$ görünümde olduğu izlendi. Pankreas ve sağ böbrek kesitlerinin otolitik ve kanamalı olduğu, dalak kesitlerinin konjesyone, sol böbrek yüzeylerinde pyelonefritik nedbeler ve kesitlerinde otoliz alanları tespit edildi. Uterus ve overler izlenmedi. Batında makroskobik olarak yoğun peritonit bulgusu görülmedi. Batın ameliyatının gerçekleştĭgi cerrahi alanın temiz olduğunu saptandı. 




Resim 1. Perikard boşluğunun şilöz sıvı ile dolu olduğu görülmektedir.

Histopatoloji raporunda; kalpte myosit stoplazmalarında genişleme, perivasküler lipomatozis ve fibrozis, epikardiyal yağ dokuda nötrofil lökosit infiltrasyonu ile hemoraji alanları; akciğerlerde ödem, konjesyon; karaciğerde mikro-makroveziküler yağlanma, konjesyon, portal alanlarda fibröz doku artışı, lenfositik infiltrasyon, inkomplet nodülasyon formasyonu; dalakta ve pankreasta otoliz; böbreklerde konjesyon, otolitik değişiklikler; ince ve kalın bağırsaklarda serozal yüzde yoğun nötrofil lökosit infiltrasyonu, kalın fibrinli eksuda tabakası, ödem, konjesyon, otoliz bulguları, subserozal alanda parlak röfle veren yabancı materyal (sütür materyali) izlendi. Sistematik toksikolojik inceleme sonucunda; kanda etanol, kanda ve idrarda sistematik yöntemlerle aranılan uyutucu uyuşturuculardan hiçbirisi bulunmadı. Perikard boşluğundan alınan sıvının biyokimyasal analizinde; trigliserid $461 \mathrm{mg} / \mathrm{dL}$, kolesterol $114 \mathrm{mg} / \mathrm{dL}$ bulundu.

Birinci Adli Tıp İhtisas Kurulu raporunda; kişinin ölümünün insizyonel herni ve divertikül perforasyonu, ileus ve gelişen komplikasyonlar sonucu meydana gelmiş olduğu ve maruz kaldığı yaralanma ile ölümü arasında illiyet bulunmadığı bildirildi.

\section{Tartışma}

Perikardiyal boşlukta şilöz effüzyon birikmesi "şiloperikardiyum" olarak adlandirılmakta olup (1,2), perikardiyal effüzyonun nadir görülen, ancak hayatı tehdit edebilen bir formudur (2-5). Hastaların bazıları asemptomatik klinikle karşımıza çıkabileceği (6) gibi, bazıları da kardiyak tamponad kliniği $(2,3,5,6)$ ile karşımıza ç1kabilir. Perikardiyal boşluktan elde edilen süt görünümlü şilöz sıvının analizinde; yağ, yüksek düzey trigliseridler, proteinler ve artmış lenfosit konsantrasyonu bulunur (7).
Olgumuzun otopsisinde perikard boşluğunda saptanan beyaz renkli, şilöz sıvının biyokimyasal analizi ile trigliserid ve kolesterol içerdiği teyit edilerek şiloperikardiyum tanısı konuldu.

Şiloperikardiyum, bir patolojiye sekonder (3,4,7-12) veya primer $(7,13,14)$ olabilmektedir. Sekonder şiloperikardiyum; cerrahi işlemlere $(3,4,7,10-12)$, vena cava, subclavian ven gibi torasik kanal veya bağlantılarındaki venleri tıkayıcı trombüslere $(7,4,15)$, lenfanjiomaya (7), mediastinal tümörlere (7-9), kistik higromaya (7) ve radyasyon maruziyetine (7) sekonder olarak oluşabilir. Şiloperikardiyumun tüberküloz veya cerrahi dışı travmadan da ileri geldiğini ifade eden yayınlar olduğu bildirilmektedir (5). Şiloperikardiyum, ameliyat sırasında duktus torasikusa drene olan küçük perikardiyal kanalların ve/ veya timus bezi içi kanalların istenmeyen biçimde hasar1 sonucunda veya çıkan aorta, inferior ve superior vena cava turnike ile sıkıldığında oluşabilir (12). Duktus torasikusta hasar olması ve duktus torasikusta artmış olan basınca bağlı perikardiyal lenfatiklere şilöz sıvının reflüsü olabilmektedir $(12,15)$.

Primer şiloperikardiyumun patofizyolojisi net değil$\operatorname{dir}(7,13,14)$. Primer şiloperikardiyum nedenleri arasında: a-Duktus torasikusun tıkanması, b-Sağ torasik kanala kollateral drenajı kurmadaki yetersizlik, c-Perikardiyum ve kalbin lenf drenajını sağlayan normal lenf kanallarında şilöz lenfin reflüsü, d-Torasik ve perikardiyal lenfatikler arasında anormal bağlantılar ileri sürülmektedir (14). Primer şiloperikardiyum tanısı konulabilmesi için sekonder tüm nedenler dışlanmalıdır.

Şiloperikardiyum ile şilotoraks birlikte bulunabilmektedir $(4,8,9,16,17)$. Şiloperikardiyum ile şilotoraksın birlikte bulunduğu bir olguda ilginç bir şekilde $1.5 \mathrm{~cm}$ 'lik mezenterik lenfanjiektazi ve familial hipobetalipoproteinemi saptanmıştır (17). Uzun süredir miyelofibrozis ve trombositoz tedavisi görürken ölen bir başka olgunun otopsisinde, sol subklavian vendeki santral venöz kateterinden kaynaklanmış sol duktus torasikusta trombüs, şiloperikardiyum ile şilotoraks saptanmış ve kişinin kalp tamponadından öldüğü bildirilmiştir (4). Tümörlü olgularda da şiloperikardiyum ile birlikte şilotoraks bulunabilmektedir $(8,9)$.

Cerrahi girişimler sırasında, şilöz kaçağın kontrolü hayati öneme sahiptir. İnce lenfatik duvarlar, az pıhtılaşabilir materyal içerdiğinden dolayı kontrol aracı olarak elektrokoter güvenilmez olabilir. Bu problem, elektrokoter kullanımından ziyade, diseksiyon sırasında timik vasküler yapıların cerrahi ligasyonu ile önlenebilir (3). Primer şiloperikardiyumun cerrahi tedavisinde ligasyon $(3,18,19)$, perikardiyektomi (18), torakoskopi ile yap1lan perikardiyal pencere aracılığıyla torasik kanalın re- 
zeksiyonu (19) bir tedavi seçeneğidir. Torakoskopi, açık cerrahi kadar hassastır, daha az invazivdir. Hızlı iyileşme sağlanır ve minimal skar kalır (19). Cerrahi için lenfanjiografi ile elde edilen bilgiler önemlidir (14). Primer şiloperikardiyum, cerrahisiz de başarılı tedavi edilebileceğinden (20), öncelikle konservatif tedavi denenebilir. Perikardiyosentez yapılmalı ve orta zincirli trigliseridlerden zengin diyet verilmelidir; cevap yetersiz kaldığında, cerrahi tedavi gereklidir (14).

Olgumuzun olayla ilgili adli tahkikatı, tıbbi evrakı, otopsi bulguları ve analiz sonuçları incelendiğinde; kalp posterior yüzeyinde üstte peteşi alanları ve epikardiyal yağ dokusunda yer yer kontüzyon alanlarının kişiye uygulanmış olan kardiyopulmoner resüsitasyon ile oluşmasının mümkün olduğu kanaatine varıldı. Olgunun vücudunda travmaya sekonder şiloperikardiyumu açıklayacak bir bulgu saptanmadı. Kişinin ölümü ile bir hafta kadar önce maruz kalmış olduğu darp arasında illiyet bulunmadığı bildirildi. Kişi bağırsaklarla ilgili ameliyat geçirmiştir. Bu nedenle, şiloperikardiyumun geçirilen cerrahi girişime sekonder olduğu kanaatine vardık. Sunulan olguda olduğu gibi, herhangi bir olguda bir patoloji saptanması halinde, bunun nedensellik bağının belirlenmesi adaletin sağlanması için büyük öneme sahiptir.

\section{Kaynaklar}

1. Barton JC, Durant JR. Isolated chylopericardium associated with lymphoma. South Med J. 1980;73(11):1551.

2. Ateş A, Erkut B, Yekeler İ. Mitral kapak replasmanı sonrası şiloperikardiyum. AÜTD 2002;34(1):17-9.

3. Gowani SA, Khowaja AA, Khan A, Fatimi SH. Chylopericardium-a rare complication after ventricular septal defect repair. J Pak Med Assoc. 2008;58 (4):218-9.

4. Smedts F, Kubat K, Chande H. Chylopericardium and chylothorax, resulting from a catheter to the left subclavian vein: an autopsy report. Klin Wochenschr. 1989;67(23):1214-7.

5. Cho BC, Kang SM, Lee SC, Moon JG, Lee DH, Lim SH. Primary idiopathic chylopericardium associated with cervicomediastinal cystic hygroma. Yonsei Med J. 2005;46(3):439-44.

6. Erol MM, Kaplan ST, Kaplan S, Türüt H, Tekinbaş C. Management of Spontaneous Idiophatic Chylopericardium, Review of the Literature. İzzet Baysal Tip Fakültesi Dergisi 2011;6(1):11-5.
7. Cervantes-Salazar JL, Calderón-Colmenero JE, RamírezMarroquín S. Idiopathic chylopericardium. A case in point. Rev Esp Cardiol. 2007;60(8):884-5.

8. Revere DJ, Makaryus AN, Bonaros EP Jr, Graver LM. Chylopericardium presenting as cardiac tamponade secondary to an anterior mediastinal cystic teratoma. Tex Heart Inst J. 2007;34(3):379-82.

9. Mogulkoc N, Onal B, Okyay N, Günel O, Bayindir U. Chylothorax, chylopericardium and lymphoedema--the presenting features of signet-ring cell carcinoma. Eur Respir J. 1999;13:1489-91.

10. Campbell RM, Benson LN, Williams WW, Adatia I. Chylopericardium after cardiac operations in children. Ann Thorac Surg. 2001;72(1):193-6.

11. Papaioannou Y, Vomvoyannis A, Andritsakis G. Combined chylopericardium and chylothorax after total correction of Fallot's tetralogy. Thorac Cardiovasc Surg. 1984;32(2):115-6.

12. Yıldırım T, Selimoğlu Ö, Çevik C, Öztürk İ, Öz FM, Kurtoğlu N, Oğuş NT. Chylopericardium following double valve replacement. Turkish J Thorac Cardiovasc Surg 2009;17(4):296-8.

13. Ross P, Joseph S, Walker D. A case of isolated primary chylopericardium. Br Heart J. 1979;41(4):508-11.

14. Kawano H. Primary chylopericardium. J Cardiol Cases. 2012;5:e173-4.

15. Kwon JB, Choi SY, Kim CK, Park CB. Primary idiopathic silent chylopericardium. J Cardiothorac Surg. 2013;8:28.

16. Salcı H, Yılmaz Z, Bayram AS, Yalçın E, Kaya M. Medical and Surgical Treatment of Chylothorax in a Dog with RightSided Heart Failure. Turk. J Vet Anim Sci. 2009;33(2):16570.

17. Wilmshurst PT, Burnie JP, Turner PR, Kubie A. Chylopericardium, chylothorax, and hypobetalipoproteinaemia. $\mathrm{Br}$ Med J (Clin Res Ed). 1986;293:483-4.

18. Hattori H, Dakeshita E, Nakazato J, Takahashi T, Wake M, Hirata K, Yasumoto H, Tengan T, Mototake H. Primary chylopericardium treated by surgery: report of two cases. J Cardiol Cases. 2011;3:e106-10.

19. Mitsui K, Namiki K, Matsumoto H, Konno F, Yoshida R, Miura S. Thoracoscopic treatment for primary chylopericardium: report of a case. Surg Today. 2005;35(1):76-9.

20. López-Castilla JD, Soult JA, Falcón JM, Muñoz M, Santos J, Gavilan JL, Rodríguez A. Primary idiopathic chylopericardium in a 2 month old successfully treated without surgery. J Pediatr Surg. 2000;35(4):646-8. 